\title{
Gender mainstreaming in rural road construction/usage in Ethiopia: impact and implications
}

\author{
Abraham Abhishek MA \\ Programme Manager, MetaMeta, Wageningen, the Netherlands \\ (corresponding author: aabhishek@metameta.nl) \\ Cecilia Borgia PhD \\ Independent consultant, Milan, Italy \\ Kebede Manjur MSC \\ Assistant Professor, Mekelle University, Mekelle, Ethiopia
}

\author{
Frank van Steenbergen $\mathrm{PhD}$ \\ Director, MetaMeta, Wageningen, the Netherlands \\ Letty Fajardo Vera BSC \\ Associate, MetaMeta, Wageningen, the Netherlands
}

This study investigated the engagement of men, women spouses (WS) and women heads-of-household (WHH) in the planning and construction of rural roads in two Ethiopian districts of Tigray and Amhara, and the differential impacts of rural roads on the mobility and transport of men, WS and WHH. The fieldwork established that there is a strong demand among women for both road use and employment opportunities in road construction. Compared with men, women demonstrated specific priorities with respect to rural road development, such as access to ambulance services, flat, wide and levelled roads, and improved access to means of transport. Although women's concerns have been slowly but steadily pushed up the planning agenda, there are gaps between gender provision in rural road development and implementation. The benefits of roads for women can be enhanced by targeting gender mainstreaming provisions to take into account the specific travel and transport needs of WS and WHH.

\section{Introduction}

Low-volume rural roads (LVRRs) provide essential connectivity for rural populations in Ethiopia. Since 1944, the government of Ethiopia has been investing extensively in rural roads development, recognising roads as a key component of agricultural development and poverty-alleviation strategies (Emmenegger, 2012). Specific evidence of the positive value of Ethiopian rural road investments is provided by Dercon and Hoddinott (2005), who showed that improvements in road quality increase the likelihood for women of selling artisanal products by $39 \%$, and by Dercon et al. (2009), who studied the impact of agricultural extension and rural roads on consumption growth and poverty from 1994 to 2004. Ethiopian successes are also highlighted by Banjo et al. (2012: pp. 147-148) in a wider review of sub-Saharan African's rural transport challenges. The bulk of Ethiopia's roads are now being built through the Productive Safety Net Program (PSNP) - a rural social protection programme that combines public assets development with employment guarantee to chronically food-insecure households. An estimated US\$200 million is spent annually under the PSNP on LVRRs. From time to time, these LVRRs are upgraded under the Universal Rural Road Access Program (URRAP). URRAP projects employ both members of local communities and skilled workers from elsewhere.

Mainstream thinking considers road development to be unquestionably beneficial to all sections of society, with few discernible harmful effects, except for those who lose land to new roads/road extensions, and is an effective means to reduce poverty (Bryceson et al., 2008). All individuals interviewed as part of this study - including women and men from road-adjacent communities, officials and transport entrepreneurs - viewed road development as desirable. However, the benefits derived from road connectivity are variably distributed. For example, off-road communities, especially women whose mobility can be restricted by social norms and limited access to cash, may suffer social and economic losses from market reorganisation along newly constructed/upgraded rural roads (Porter, 1995). A recent study in Tigray conducted by Rammelt and Leung (2017) used causal loop diagrams to demonstrate that while road infrastructure can bring widespread benefits, improved mobility may further strengthen the competitive advantage of farming households with higher surpluses and higher incomes, thereby widening the gap between them and subsistence producers. A study of transport and mobility in rural Ethiopia by Bryceson et al. (2008) attributed the disadvantages faced by low-income households to their lower access to motorised transport.

Existing studies on the impacts of rural road development in Ethiopia present two major gaps. First, they do not sufficiently address the gender-based impacts of rural road development on mobility, making inadequate distinctions between women in male-headed households (MHH) and women heads-ofhousehold (WHH). Second, questions remain as to how the differential impacts of roads are linked to intra-household gender relations and task allocation, with particular reference to the varied travel patterns, needs and access to rural transport services of men, women spouses (WS) and WHH. 
Despite community roads constituting more than two-thirds of the total road network in Ethiopia, there is a lack of information on road development at the community level and the available records on women's participation in planning and construction are few and contradictory (Emmenegger, 2012; ERA, 2019). According to Emmenegger (2012), women's engagement in state-led community rural road construction is negligible. While women are not excluded in the selection procedure in principle, social and gender norms restrict their numbers in practice. A different situation is found in the PSNP design, where women's participation in public works is strongly encouraged through the introduction of gender-specific provisions meant to alleviate women's work burden and maximise their benefits from the programme. However, gaps remain at the level of implementation of gender-sensitive policies in rural road development and information is scant about how these policies translate into practice.

Based on field research conducted in 2016-2017 in two woreda (districts) in northern Tigray and Amhara, this paper contributes to improved understanding of

the engagement of men, WS and WHH in the provision of rural roads in Ethiopia's Tigray and Amhara regional states

- their participation in and benefits from road construction and maintenance

- the impact of rural roads on mobility and transport of men, WS and WHH.

\section{Researching road development, transport usage and gender in Ethiopia}

\subsection{Rural road development}

Compared with other African countries, Ethiopia is not trapped in 'tarmac bias' (Chambers, 1983), whereby off-road communities are neglected. Instead, large investments have been made in low-quality rural roads with the aim of improving the access of remote villages to socio-economic services.

The total classified all-weather road network in 2013 was around $86000 \mathrm{~km}$, of which $28000 \mathrm{~km}(33 \%)$ of rural roads had been constructed under the URRAP in just 3 years from its inception in 2010 (Sampson et al., 2014). During its first phase (ending 2015), the URRAP increased the number of connected kebeles (the smallest administrative units in Ethiopia, akin to sub-districts) from 6222 to 11876 (ENA, 2016). Rural roads are also a central element of the PSNP. As of February 2016, $39000 \mathrm{~km}$ of rural roads had been developed under the PSNP through concerted efforts by successive regimes that began in the early 1940s. However, despite political will and substantial investment, the achievement in terms of kilometres constructed remains below planned due to, among other reasons, Ethiopia's difficult terrain that renders construction costs very high (Bryceson et al., 2008). Consequently, on average, rural households are still more than $10 \mathrm{~km}$ away from a dry-season road and $18 \mathrm{~km}$ from public transport services (ERA, 2019).

While national transport policies and programmes recognise that transport services should be made available in tandem with the construction or upgrading of rural roads in order to improve mobility meaningfully, road development is still not sufficiently integrated in wider development interventions and connected to the provision of rural transport options (Bryceson et al., 2008; Mahapa and Mashiri, 2001). Nevertheless, investments in better rural roads in Ethiopia have had a positive impact on access to schooling, health care, safe child delivery, agricultural inputs and outlet markets (Bryceson et al., 2008; Rammelt and Leung, 2017; Rammelt et al., 2017). On the other hand, accessibility enhancements have not been followed by equal mobility gains (Bryceson et al., 2008; Rammelt and Leung, 2017).

Without public investment in rural transport, low-density remote areas cannot generate a critical mass of customers to attract private transport services. As a consequence, rural Ethiopia remains an overwhelmingly walking country, regardless of whether the village is well connected or remote and with or without road improvements (Bryceson et al., 2008) (see Figure 1).

\subsection{Rural road development in Ethiopia}

Major federal and regional trunk and link roads fall under the responsibility of the federal Ethiopian Roads Authority and

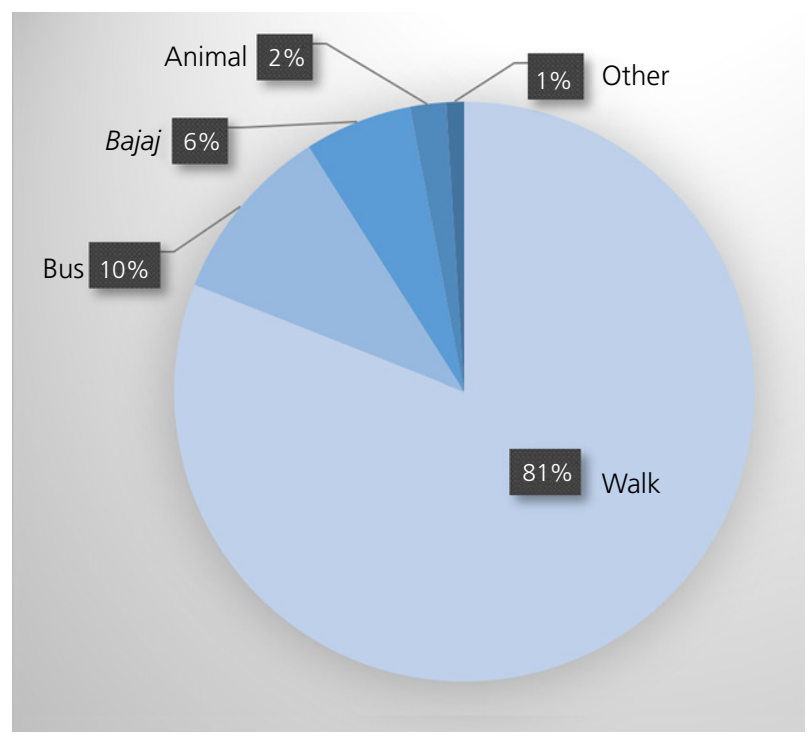

Figure 1. Ethiopia: an overwhelmingly walking country breakdown of trips undertaken by households over a typical year. Data based on interviews with 529 households (110 headed by females and 419 headed by males) conducted in

August-September 2016 
the regional governments' Rural Roads Authority. Since 2001, however, the expansion and maintenance of the rural road network, with the exception of high-standard rural roads, has been devolved to the district level and is the responsibility of the Woreda Rural Roads Offices (WRROs).

This focus of this study was on LVRRs developed under the URRAP and PSNP and characterised by having an average daily traffic volume of 2-3 vehicles (BCRT, 2016). These small roads are inter-kebele links and those connecting kebeles to smaller towns or to main roads (the latter known as 'feeder roads'). They are classified by the Ethiopian Roads Authority as community roads from a political perspective (because they are administered by the WRROs) and as feeder roads from a functional perspective. In this paper, the terms feeder road and community road are thus used interchangeably.

Rural road development in Ethiopia typically takes place in stages. A rural road starts as a footpath or trail that has evolved over time with little or no engineering intervention (ERA, 2008). It is a logical foot and/or animal path used to reach other villages, larger towns or livestock markets. Footpaths are constructed with voluntary labour, mobilised and organised by the local leadership. Such low-quality paths are not suited to motorised transport, although the occasional lorry or pick-up truck may pass through them. Subsequently, a footpath may be upgraded to a community road/feeder road. This implies widening and levelling works and clearing vegetation, possibly with some basic drainage structures that need annual maintenance. In Ethiopia, the majority of feeder roads are constructed through the PSNP. Beneficiaries provide the required unskilled/semi-skilled labour, and are paid through a combination of cash and food (World Bank, 2010). A community road can further be upgraded with masonry work, drainage facilities and stream-crossing structures (e.g. bridges, fords, culverts) under the URRAP. Masonry work requires skilled labour and offers higher wages. Usually, such labour is hired by the contractor from elsewhere, although unskilled labour may be hired from within the road-side community, including PSNP beneficiaries.

Hard data on the level of engagement of women in construction are scarce (Subbarao et al., 2013) but the available information points to their low participation in Ethiopia (Emmenegger, 2012).

\subsection{Rural roads and transport in the two study districts}

The two study districts were Kilte Awlaelo (Tigray) and Kobo (Amhara).

Kilte Awlaelo district is situated in a mountainous area in north-east Tigray. The local economy is based mainly on agriculture. Irrigation development from the 1990s has enabled small- and large-scale commercial horticultural production, generating relatively high farming incomes. However, development interventions aimed at intensifying agriculture in Tigray through irrigation projects, subsidised inputs and improved seeds have been patchy, covering only about $15 \%$ of the regional cultivated area (Hailu, 2009). Several tabias (village clusters) in Kilte Awlaelo, located in rugged topography unsuitable for intensive agriculture, have not been connected to markets and services and thus remain isolated. Although there have been some increases in vehicular and animal-driven transportation in Kilte Awlaelo as a result of the extension and improvement of the rural road network, this has been sporadic. Limited transport options adapted to rural roads, low transport frequency and unaffordable travel fares remain barriers to mobility enhancements (Rammelt and Leung, 2017). Available motorised transport modes comprise mini- and midi-buses that provide regular services within and between urban centres, but these operate on LVRRs only on market days when there is high demand. On other days, people have no other option than to walk or use a bajaj (motorised three-wheeler rickshaw). This implies a gap between the need for motorised transport and the availability of options.

Kobo woreda, in the north-east of Amhara, has flatter terrain. Here, rain-fed cereal and fodder subsistence farming predominates. Like Kilte Awlaelo, Kobo suffers from a scarcity of motorised transport options, although animal-drawn carts (mainly donkey-pulled) are more prominent than in Kilte Awlaelo due to the flatter terrain. Whereas most rural households own donkeys and men and women equally use them, donkey carts are mostly owned by MHH and used by men.

Larger-wheeled motorcycle-based three-wheelers have not yet spread in Tigray and Amhara: motorised three-wheeler options are limited to the much less rurally appropriate, small-wheeled scooter-based vehicles, bajaj and piaggios. Piaggios are much more commonplace in Kilte Awlaelo where their operational costs and margins can be met by the higher incomes from irrigated vegetable production and the need to transport large volumes of perishable agricultural produce. Bicycles are unusual in the rural areas of the study woredas; where available, they are mostly ridden by men and boys.

\subsection{Gendered experience in rural road and transport use}

The two study districts, much like the rest of rural Ethiopia, suffer from an overall scarcity of appropriate transport services. While road development has accelerated recently, much more progress needs to be made before the road infrastructure capacity can be fully utilised. This would bring benefits to women and men alike. However, women have some specific transport-related needs and experiences that are distinctly different from those of men. Four key aspects define the gendered differences in travel experiences - income differentials, gender roles and travel purposes, dealing with crowding and travel safety. These factors are now addressed in turn. 


\subsubsection{Income differentials}

Households with WHH tend to have lower income than MHH because they commonly lack access to labour and oxen. Even when WHHs own oxen, social norms prevent them from using them (Marshall and Ali, 2004). Instead, WHHs engage in sharecropping agreements, which halve their potential farming income. WS are usually financially stronger than WHH as their households have two working adults rather than one. They can thus spend more on travel. However, this benefit is offset to some extent by the greater freedom WHH have to make financial decisions on how they spend money, since male heads have greater control over disposable income and assets in $\mathrm{MHH}$. Typically, men spend more on transport than either their spouses or WHH.

In terms of travel experience, this translates into men being more likely to

- take the bus rather than walk to the nearest town on market days, thus spending less time on travel and being less exposed to road dust

- summon a bajaj on non-market days when mini- or midi-buses are not available

- travel more frequently, and for greater distances, compared with WS and WHH (in that order).

\subsubsection{Gender roles and travel purposes}

The inadequacy of road infrastructure and transport options limits the mobility of both women and men. However, much like elsewhere in sub-Saharan Africa, patriarchal institutions that shape daily social practices affect different travel patterns and purposes among women and men (Porter, 2011; Starkey and Hine, 2014).

Women are in charge of repetitive chores such as fetching water and collecting firewood: this requires them to travel on underdeveloped paths rather than on roads and on foot rather than by other means of transport. Women and girls also shoulder the responsibility of selling low-volume farm produce at market (e.g. teff, barley, maize, chickpeas) and buying household supplies. This means more market trips for women than for men, who are mostly in charge of selling livestock and may travel to market with bigger, heavier loads, but only around harvest time. Household-related responsibilities exclusive to women also make them less flexible in their travel planning. On market days, women must finish their market business and travel back home as soon as possible so that they can attend to chores like preparing dinner for the evening. Men, by contrast, can wait until later before beginning their return journey, when the sun is less harsh.

Typically, women and girls may spend up to $10 \mathrm{~h}$ per day on tasks that potentially increase the burden on their time and wellbeing substantially beyond that experienced by men.

\subsubsection{Dealing with crowding}

With demand for transport outstripping the availability of mini- and midi-buses, crowding is inevitable. Men and women experience and deal with this very differently: 'If we were men, we could elbow our way through the crowd and capture the empty seats', explained a WHH interviewed in Kilte Awlaelo woreda. Women are less inclined to squash themselves into a crowded bus, especially a bus crowded with many men. When travelling with young children - as women often do - or during pregnancy, crowded buses are not even considered an option: 'In such circumstances, we don't wait for the bus, we just walk', agreed women in Woroma, who travel regularly to Wukro town, $7 \mathrm{~km}$ away.

\subsubsection{Travel safety}

Vehicular safety is an important issue for both women and men. For example, despite valuing bajajs for filling a key transport gap, both groups expressed apprehensions about the safety risks associated with them - the small wheel base, the relatively tall design and the weak $12 \mathrm{hp}$ engine make for an unstable vehicle, especially on steep, bumpy, rural roads. However, a key difference between women (both WS and WHH) and men manifests itself in the area of personal safety. Respondents in the field research - men, WS and WHH agreed that women are far more vulnerable to sexual assault. In almost all interviews with women and men, the risk of sexual assault on women was recounted as a possibility that has to be factored into travel plans. As a result, women try to travel in groups and do not travel late in the evening.

\section{Methodology}

The research findings presented are based on joint field research by MetaMeta (the Netherlands) and Mekelle University (Ethiopia) in two road-adjacent communities. The research team comprised two women and two men. For the study, a mixed methods approach was used comprising diverse qualitative and quantitative research methods to explore the multiple dimensions of gender, rural roads, transport and mobility. Focus group discussions and semi-structured interviews with men and women were conducted to investigate gender dimensions in rural road provision and employment opportunities in road construction for women, as well as the different travel and transport experiences of men, WS and WHH. Moreover, through use of PhotoVoice, the research team aimed to capture qualitative insights into women's experiences of mobility and transport access on feeder roads. This draws on the concept of participatory photography/video with disadvantaged groups through a participatory process that can also empower them as it documents the participants' own perspectives regarding needs and resources.

LVRR segments around main woreda towns (Wukro in Tigray and Kobo in Amhara) were selected, and villages and sites for interviews and focus groups were identified with the help of woreda authorities. The selection was guided by the objective 
to include both marginally connected and more connected households. In total, 181 women (64 WHH and $117 \mathrm{WS}$ ) and 163 men were reached through focus groups, semi-structured interviews and PhotoVoice. In Amhara, 104 girls and women (including $40 \mathrm{WHH}$ and $13 \mathrm{WS}$ ) and 124 men were interviewed in eight villages. In Tigray, the study drew upon 77 women (including $24 \mathrm{WHH}$ and $45 \mathrm{WS}$ ) and 39 men respondents in eight villages. Analysis of this qualitative data helped to identify the themes and issues recurring frequently during the interviews - notably the first-mile connectivity, the ambulance service, bus fares, road quality and employment opportunities in road construction - and the differences between the opinions and importance attached to them by WS, WHH and men.

To complement the qualitative data, a quantitative survey was conducted with $65 \mathrm{WHH}, 65 \mathrm{WS}$ and 65 men in Kilte Awlaelo and Raya Kobo. The data were collected by trained enumerators who were closely supervised by the research team. The collected data were coded and then analysed using SPSS software. In total, the research covered 539 residents of roadadjacent communities. The qualitative data were complimented with two rounds of quantitative data collection. A baseline survey was conducted among 529 households to collect data regarding general patterns of rural road and transport usage in the research area. The survey preceded the official start of the research. A second survey followed the focus group discussions, semi-structured interviews and participatory photography exercises; this survey was designed to supplement the qualitative data and was conducted with 195 respondents (65 WHH, 65 WS and 65 male heads-of-household). Apart from road and transport use, these surveys also focussed on questions related to women's participation in road planning and construction.

Field research and data collection were carried out in three rounds (November 2016, January-February 2017 and March 2017) with at least one female researcher involved in each round. Between rounds, two workshops were organised, which helped to triangulate the data and enhance the rigour of the analysis. Supplementing this core data were interviews with key informants, including stakeholders in government organisations involved in designing and implementing the PSNP, road development, gender, and transport policy and programmes.

\section{Women's participation in road planning: gaps and progress}

The fieldwork established that there is a strong demand among women for appropriately designed roads and employment opportunities in road construction, despite their relative time poverty. However, women only participate in road development when enabling conditions and employment opportunities are created for them. Women's participation in the planning of works is key to creating these enabling conditions. When the decisions taken are not informed by women's concerns and interests, the employment opportunities created are biased towards men. This bias is in the form of favouritism around certain kinds of works involving hard physical labour where men have a distinct advantage, as well as the choice of tools/techniques used (Holmes and Jones, 2011).

In Ethiopia, the engagement of women in rural road planning and implementation is embedded in the participatory planning approach that the government has adopted as the cornerstone of the PSNP (Mard, 2009). Planning is organised by decentralised administrative structures at woreda, kebele and village levels, and construction relies largely on community participation (World Bank, 2010). Development committees and taskforces at kebele level engage communities to identify and prioritise public work needs and to assess and mobilise labour contributions from each household (Mard, 2009). These bodies include representatives of women's and men's groups, tasked with raising the concerns and needs of their constituents.

The PSNP gender action plan proposes a number of measures to capture gender issues better, such as

holding separate consultations for women and men, if necessary

- initiating experience-sharing processes among women

- taking affirmative action towards increasing women's participation in committees and leadership positions

- targeting women with awareness-raising campaigns regarding different government programmes

- holding gender-sensitisation training

- using gender-disaggregated data to prioritise works in particular areas.

Additionally, emphasis is placed on women's capacity-building through training provided by government-employed extension workers, in a range of technical areas such as financial management, farming and irrigation, environmental issues and gender mainstreaming provisions (MoA, 2014). Discussions with women in several villages around Wukro town highlighted that, thanks to these training sessions, women have become more vocal about their personal and household needs. Importantly, the training underlined the importance of women's participation in the public sphere in the eyes of men. A male respondent in Wukro woreda reported that if a husband does not let his wife participate in meetings, he is given a hard time by the authorities. Along with federal-level directives to achieve 50\% representation of women in administrative bodies, the PSNP gender action plan guides efforts at regional, woreda and kebele levels to promote women's participation in public works planning.

However, gaps certainly remain between gender-sensitive provisions and their implementation on the ground. Local administrations often struggle to achieve the targets for representation of women in taskforces and committees. Men continue to dominate leadership positions and their opinions are more likely to be taken into account than those of women (Jones et al., 2010; personal communication with PSNP 
taskforce in Kilte Awlaelo, 2017). Women thus have limited opportunity to negotiate start times for working on the road that fit their daily household and childcare activities, despite PSNP guidelines stating that public works must be flexibly adapted to women's activities (see Figure 2).

Prevailing socio-cultural norms limiting women's participation in decision-making apply both to WS and WHH. However, any difference in the levels of participation of WS and WHH is determined by the interplay of two opposing pressures. On the one hand, WHH experience greater time poverty since they also must carry out tasks that men would undertake in households headed by a couple. This leaves them with less time to attend public meetings. On the other hand, WHH are the primary decision-makers in their households so, if they are willing to participate in discussions related to road planning, there is no one to dissuade them from doing so. In contrast, the traditional role of WS in household decision-making is as deputies of their husbands. Thus, it is invariably the husbands who participate in public meetings.

These gaps should be viewed in the context of the difficult nature of the objectives of gender mainstreaming provisions. Instances of incremental progress in gender mainstreaming are increasingly visible. For example, Adi Kesandet kebele in Tigray regional state has been successful in reaching its target of women representatives on its various committees and taskforces. In several villages, women feel that their participation has significantly contributed to livelihood improvements for the entire community. For instance, in Buku (Amhara), a remote settlement $5 \mathrm{~km}$ away from the nearest feeder road leading to Kobo town, by participating in planning meetings and repeatedly airing their views, women were able to achieve two long-standing demands - connection to the ambulance service through the development of a feeder road and construction of wells in their village to cut down the time they spend fetching water. At a more macro level, there is now clear recognition of the need to connect villages with ambulance services for pregnant women as a criterion for approving requests for building feeder roads. This is a result of continual efforts to encourage more WS and WHH to participate fully in the process of road infrastructure planning.

\section{Employment opportunities for women in road construction}

\subsection{Implementation of gender provisions in road construction}

A wide range of gender mainstreaming provisions is embedded in the PSNP design to facilitate the participation of women in the construction and maintenance of feeder roads and increase their ability to benefit from employment opportunities. The provisions aim to take into account women's relative time poverty and socio-cultural norms regarding their suitability to undertake different kinds of physical labour (MoA, 2014). However, field research revealed that the level of implementation of these provisions varies substantially across various regions, woredas and kebeles. Some of the most widely implemented provisions include the following.

- Relaxed obligations for WHH to provide labour for the PSNP. Regarding work obligations, every household member is allocated $5 \mathrm{~d}$ of work per month. It is the responsibility of the household head (and the spouse if there is one) to provide this allocated amount of labour to PSNP work. Within a MHH, the male head and his spouse have to provide $15 \mathrm{~d}$ and $10 \mathrm{~d}$ of labour, respectively. Male heads-of-household who are single must provide $15 \mathrm{~d}$ of labour while WHH have to work only $10 \mathrm{~d}$.

- Relaxed daily work targets for WS and WHH, compared with those for men. As per the PSNP project implementation manual (MoA, 2014), considering women's workload, their daily work quota should comprise fewer hours and fewer units of work (e.g. length of road levelled, stretch of vegetation cleared). While this provision is being implemented more widely, in many instances women still end up contributing equally, being only exempt from hard physical work such as breaking and carrying big rocks.

- Paid maternity leave of up to 17 months. According to the PSNP implementation manual, women have a right to 9 months' maternity leave (from the sixth month of pregnancy until the baby's sixth month). In practice, women take leave from the fourth month of pregnancy through to one year after the birth. These additional 8 months have been negotiated by women in several

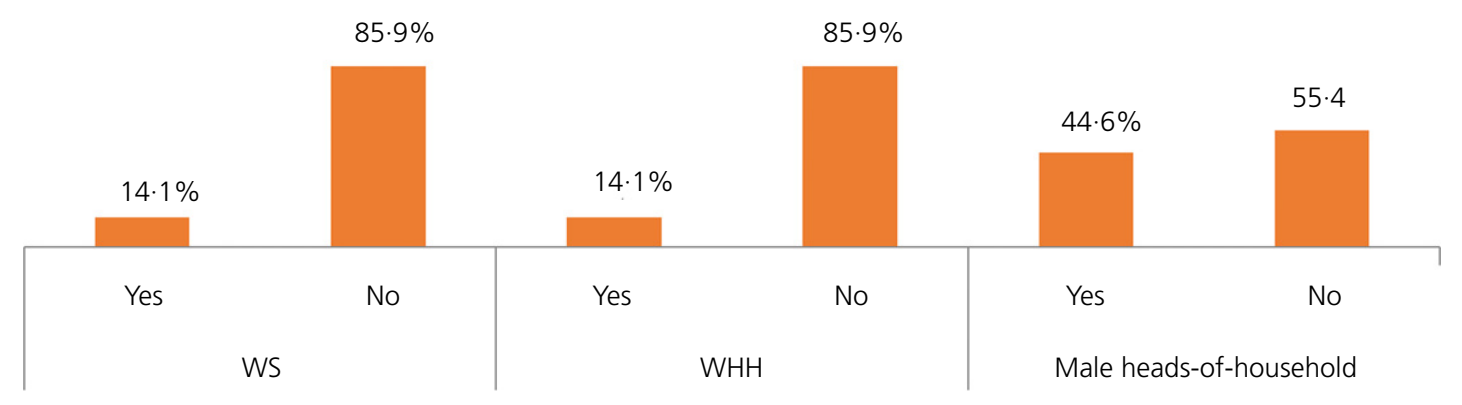

Figure 2. Responses to the question 'Do you participate in rural road planning meetings?' (65 respondents in each category) 
villages and granted by PSNP implementers. If the woman is married, the husband has to take over her work obligations for the additional 8 months.

- Exemption of the elderly and people with disabilities from PSNP work. The elderly and people with disabilities receive benefits not conditional on their participation in the PSNP.

As already mentioned, the implementation of some of the provisions is highly variable, such as the provision of childcare and flexible working hours for women (Andrews and Kryeziu, 2013). Crèches are organised under canopies where elderly, pregnant and other beneficiaries of the PSNP exempted from physical work look after the children. Yet, among 14 villages where information was sought about the presence of a crèche near the worksite, only three reported having one, with implementation rates in Tigray higher than in Amhara.

A key constraint to realising the provisions in the PSNP design appears to be a lack of awareness - both at the community level and at the level of the field officers responsible for implementation - about the various gender mainstreaming provisions (Evers et al., 2008). Moreover, as Holmes and Jones (2011) pointed out, while there is a rather large number of organisations forming the 'gender policy infrastructure' in Ethiopia, especially the 2006 National Action Plan for Gender Equality (MOWA, 2006), there is limited coordination among programmes and the sectors and organisations entrusted with implementing them.

Nonetheless, amid all these implementation gaps, a large number of women have been reached by the PSNP. Women represent $46 \%$ of the programme beneficiaries in Tigray regional state, and 37\% in Amhara (World Bank, 2008). The PSNP has helped increase household food consumption and has helped cover the cost of clothing, education and healthcare (Evers et al., 2008). Incidents of 'distress sales' of assets and premature harvesting of crops have also declined considerably (Holmes and Jones, 2011). The women interviewed in this work reported that the net effect of the PSNP has been an improvement in their economic security and enhancement in their social standing and respect. This is validated by findings of several systematic appraisals of the PSNP (Combaz, 2013; Holmes and Jones, 2011; World Bank, 2010) and interviews carried out within this research with PSNP-implementing organisations (personal communication with Wout Soer, 2016 (former coordinator of the PSNP coordination team, World Bank, Ethiopia)). This leads to the conclusion that the levels of participation of women in the PSNP are significant enough to have brought about these noticeable impacts.

\subsection{Differential employment opportunities in PSNP and URRAP roads}

While PSNP and URRAP roads are both labour-based, URRAP roads imply a higher degree of technical input and mechanisation. This has implications for the level and type of engagement of women and men in construction.

In URRAP roads, about $70 \%$ of the labour required is unskilled and sourced from the road-adjacent community. Unskilled roadworks under URRAP are divided quite neatly along gender lines. Women who manage to get hired are mainly tasked with fetching water for the preparation of concrete, carrying cement bags, mixing construction materials and watering cement structures. Men do the levelling, digging and carrying/breaking rocks and stones. The remaining 30\% is skilled labour, mostly contracted from elsewhere, and with wages thrice those of unskilled work (200 Ethiopian birr (ETB) $(\approx £ 5 \cdot 20)$ compared with 60 ETB $(\approx £ 1 \cdot 60))$. Skilled labour is required to undertake masonry work, which is viewed almost unanimously as a male job. When women and men were asked whether women could learn masonry skills and earn a higher wage, the first responses were always negative: 'It is not our tradition' and 'It is not part of our/their skill'. However, as the discussion progressed, women would say that masonry was something they could do if provided with proper training, with one female respondent in Buku (Amhara) saying 'I have never seen a woman with building or construction skills, it is not part of our culture, so I never tried to learn myself. But if there were training opportunities I would like to learn'.

In the PSNP, skilled work is not always required and the division of unskilled works along gender lines is less stark. Nevertheless, the PSNP identifies the need to allocate work to women that is 'light' (physically) and 'flexible' (taking into account their time poverty and need to arrive late and leave early). Overall, the PSNP guidelines lay down the need to reduce women's workload by $50 \%$ (MoA, 2014). Some of the jobs considered 'light' and 'flexible' include carrying stones, digging pits/trenches, levelling surfaces and breaking smaller rocks. Men break the bigger rocks and almost exclusively carry out skilled jobs such as masonry. The PSNP lays down the same wage rate for the same work, regardless of gender (MoA, 2014). None of the more than 400 respondents recalled any instance of women being paid less for the same work. If anything, the wage rate could be said to favour women, given their lower daily targets (e.g. metres of road levelled, length of stretch cleared of vegetation etc.).

\section{Roads as routes to improved lives for women}

As discussed earlier, women bear the brunt, physically and financially, when road connectivity is inadequate and when road quality is poor. Fieldwork evidenced that there is a stronger demand for work on road infrastructure (feeder roads and tarmac roads) among women than men. Men's demand for roads is tempered by a greater concern for potential loss of land resulting from new road construction. The findings of this work highlighted that women have several key priorities 
with respect to rural road development that - if reflected in road planning - would improve their lives greatly.

\subsection{Ambulance service}

The foremost reason why women value feeder roads is that they help them connect to the government-run ambulance service that can take them to the nearest health centre during pregnancy. It is notable that men also recognised ambulances as the most important service made accessible by roads to women. Most importantly, authorities such as the Woreda Road and Transport Office recognise this and prioritise kebeles not yet connected to the ambulance service when it comes to approving requests for feeder road development.

\subsection{Good roads}

Anecdotally, women want 'good' feeder roads. Upgrading of community roads to feeder roads and improvements to feeder roads in the form of bridges and fords to improve drainage and accessibility make a huge difference to connectivity within rural areas and to urban centres. With women travelling more frequently for repetitive chores and thus bearing the brunt of bad roads and transport services, they are the first to benefit from the upgrading of infrastructure, especially regarding access to ambulance services. The Women's Bureau of Kilte Awlaelo told the research team that, thanks to the ambulance service, maternal death there is almost zero (personal communication with PSNP taskforce, 2017).

On the same note, it is important to improve first-mile connectivity - the path from the homestead to the rural road. For many respondents, this 'first mile' is $5 \mathrm{~km}$ or more. Rocky, seasonally eroded, steep, muddy and slippery first-mile stretches were presented by women as one of the biggest issues they face. In the PhotoVoice exercises, women explained what they consider to be a good road as follows.

- Free of stones. Rock outcrops and stones make roads difficult to walk on, especially during the rainy season and during pregnancy.

- Flat. In both study regions, much of the terrain is hilly and rural roads are often steep. Because women have to carry goods to and from market several times a week, they prefer to walk on flatter routes even if these are somewhat longer. Men and boys responsible for selling livestock have to walk longer distances with their animals but much less frequently and take shortcuts, no matter the gradient.

- Wide. When a number of people are walking on a road with livestock, a wide road enables groups to overtake and cross each other side-by-side, preventing congestion.

Besides, women said they felt safer walking on wider roads when vehicles pass by.

- Tarmacked. Among all women's demands for feeder roads, their best-case scenario was stated to be tarmacking of the community road as they believe this will bring motorised transport closer to their doorsteps. This was validated by the transport operators' stated reasons for not circulating on rural roads - that is, unsatisfactory road conditions. Another key reason why women want tarmacked roads is the problem of dust rising around passing vehicles. This is a health hazard that affects both those walking on the feeder roads and those living by them.

Entire communities would benefit from flatter, wider, less rocky roads, but it was mostly women who described 'a good road' as having these particular characteristics; male respondents focused on tarmacking and having masonry structures such as bridges and fords.

\subsection{Access to rural transport services}

Because of their time poverty, less access to money and greater concerns for safety and comfort, women across the spectrum, both WS and WHH, would benefit most from increased access to affordable rural transport modes. This would significantly enhance their mobility, and with it, socio-economic opportunities.

Given the generally low and variable customer base in rural areas, the key reason for poor transport services is that transport operators (almost all private entrepreneurs) do not find it profitable to ply rural roads, except on market days. Bus operators say that to increase the number of trips in rural areas they would need to increase fares by as much as $50 \%$. Current prices set by bus drivers are still often unaffordable (see Figure 3 and Table 1), especially for women who have generally less disposable income than men. The cost of transport was cited as a cause of school dropout after primary school. Bus crowding is another consequence of trying to increase the profitability of the service: midi-buses often carry up to 60 people (against the legal capacity of 20-25) and mini-buses often carry 35 passengers (against the legal capacity of 10-12). Such crowded buses are discouraging and threatening to women, especially those who are pregnant and/or carrying babies. In some villages, the uncertainty of being able to find transport discourages women from undertaking trips, which, in turn, limits their mobility and access to goods, services and social networks.

As discussed earlier, the findings underscore the point that women and men suffer from the same shortcomings of the road infrastructure and transport systems. They both aspire for, and will benefit from, the same set of improvements better roads, more transport options, cheaper fares. However, being responsible for daily chores, women travel more frequently and thus bear the brunt of the shortcomings. Women thus stand to gain more from measures to improve roads and rural transport, so long as transport fares are set at a level affordable for them. This is an important insight and a relevant guide to policymakers concerned with gender mainstreaming policy as well as rural transport. 


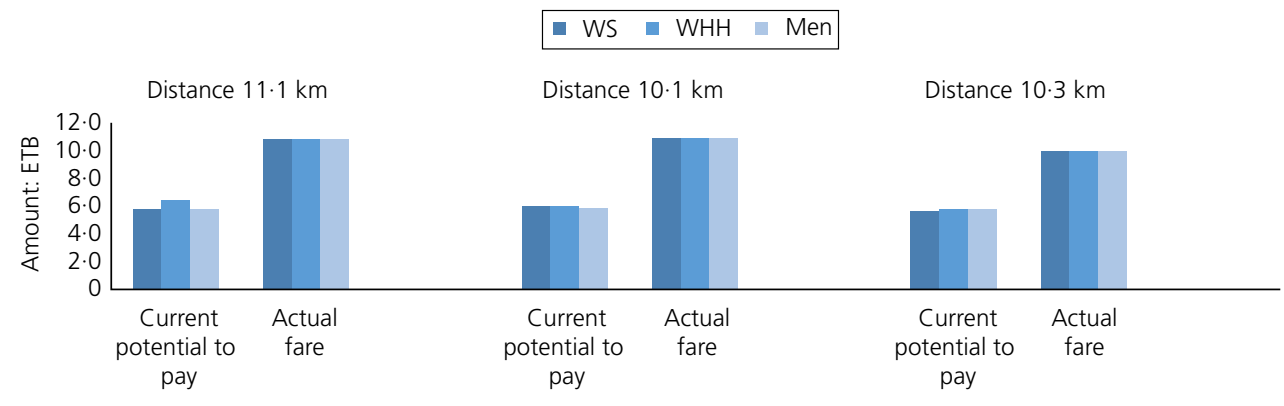

Figure 3. Comparison of respondents' potential to pay and actual fares (100 ETB $\approx £ 2 \cdot 60)$; 65 respondents in each category

Table 1. Respondents' potential to pay and actual fares $(100 \mathrm{ETB} \approx \mathrm{f2} \cdot 60)$; 65 respondents in each category

\begin{tabular}{|c|c|c|c|c|c|c|}
\hline & \multicolumn{2}{|c|}{$\begin{array}{l}\text { To nearest market centre } \\
\text { (distance } 11.1 \mathrm{~km} \text { ) }\end{array}$} & \multicolumn{2}{|c|}{ To woreda centre (distance $10 \cdot 1 \mathrm{~km}$ ) } & \multicolumn{2}{|c|}{$\begin{array}{l}\text { To woreda, all-weather roads } \\
\text { (distance } 10.3 \mathrm{~km} \text { ) }\end{array}$} \\
\hline & Potential to pay: ETB & Actual fare: ETB & Potential to pay: ETB & Actual fare: ETB & Potential to pay: ETB & Actual fare: ETB \\
\hline WS & 5.9 & $10 \cdot 9$ & $6 \cdot 0$ & $11 \cdot 0$ & $5 \cdot 7$ & $10 \cdot 0$ \\
\hline WHH & $6 \cdot 5$ & $10 \cdot 9$ & $6 \cdot 0$ & $11 \cdot 0$ & 5.9 & $10 \cdot 0$ \\
\hline Men & $5 \cdot 9$ & $10 \cdot 9$ & $5 \cdot 9$ & $11 \cdot 0$ & $5 \cdot 9$ & $10 \cdot 0$ \\
\hline
\end{tabular}

\section{Conclusions}

The findings of this research demonstrate that WHH and WS have some specific needs and demands in road development and usage, and both groups demonstrate a strong willingness to engage in road development processes. This strengthens the argument for making concerted efforts towards gender mainstreaming in rural road construction and greater engagement of women in road planning. However, gender relations and the norms that constrain women's participation in planning and decision-making in public works are rooted deep in the society and culture.

Ethiopia's experience with gender mainstreaming in the PSNP is an example of an agency with legitimacy (the government) intervening and being able to achieve incremental but significant change by providing entitlements - of cash and decisionmaking power - through a social protection programme used also to plan and build public assets. However, much progress remains to be made, especially in terms of improving women's participation in the planning of roadworks (MoA, 2014), eliminating the exclusion of women from certain work considered to be fit only for men (Holmes and Jones, 2011) and closing the gap between gender provisions and their implementation. At the same time, an accurate appraisal of the PSNP's effect on women must note that, for all its shortcomings, it has brought about significant changes to women's socio-economic standing and quality of life, especially for female-headed households (Holmes and Jones, 2011). The PSNP is highly valued by both rural women as well as government organisations whose mandate is to strengthen social protection available to women (personal communication with PSNP taskforce, 2017).

Guided by a federal directive to achieve $50 \%$ representation of women in administrative bodies, affirmative action has been taken to increase women's participation in taskforces and committees from the tabias right up to regional state level. Again, while implementation of the directive is far from perfect, it has gradually enabled more and more women to provide their inputs at various points in the planning process. Their needs and priorities are thus slowly seeping into the decision-making process.

It is significant, then, that much of rural road development in Ethiopia is happening through employment-intensive, social protection programmes like the PSNP. They create a large number of low-skilled jobs and reserve some of them for women, rather than infrastructure-focused programmes with low labour absorption. Improvement of the outcomes could be further helped through greater skills development. Gender mainstreaming provisions can be targeted better by taking into account the key differentials between WHH and WS in terms of household responsibilities and daily schedules, income and control over income and time.

\section{Acknowledgements}

The support of the Global Resilience Partnership through the programme 'Connecting roads, water and livelihoods for resilience' in developing this paper is acknowledged. Also acknowledged are collaborating institutions, mainly the Ethiopian Roads Authority and the Tigray and Amhara Bureaus of Agriculture and Rural Development. 


\section{REFERENCES}

Andrews C and Kryeziu A (2013) Background Paper for the World Development Report 2013: Public Works and the Jobs Agenda: Pathways for Social Cohesion. World Bank, Washington, DC, USA.

Banjo G, Gordon H and Riverson J (2012) Rural Transport: Improving its Contribution to Growth and Poverty Reduction in sub-Saharan Africa. World Bank, Washington, DC, USA, SSATP Working Paper 93.

BCRT (Bureau of Construction, Road and Transport) (2016) Summary Classified 2nd Round Traffic Count for Rural Road (January 2016 G.C.) for the Supervision of Road Maintenance Program for Tigray Region. BCRT, Mekelle, Ethiopia.

Bryceson DF, Bradbury A and Bradbury T (2008) Roads to poverty reduction? Exploring rural roads' impact on mobility in Africa and Asia. Development Policy Review 26(4): 459-482.

Chambers R (1983) Rural Development: Putting the Last First. Pearson Educational, London, UK.

Combaz E (2013) Social Inclusion in Productive Safety Net Programmes (GSDRC Helpdesk Research Report 1005). GSDRC, University of Birmingham, Birmingham, UK.

Dercon S and Hoddinott J (2005) Livelihoods, Growth, and Links to Market Towns in 15 Ethiopian Villages. International Food Policy Research Institute, Washington, DC, USA, FCND Discussion Paper 194.

Dercon S, Gilligan DO, Hoddinott J and Woldehanna T (2009) The impact of agricultural extension and roads on poverty and consumption growth in fifteen Ethiopian villages. American Journal of Agricultural Economics 91(4): 1007-1021.

Emmenegger R (2012) The Roads of Decentralisation: The History of Rural Road Construction in Ethiopia. NCCR North-South, Bern and Zurich, Switzerland, NCCR North-South Dialogue 39.

ENA (Ethiopian News Agency) (2016) See http://www.ena.gov. et/en/index.php/economy/item/1229-urrap-reaches-76-percentaross-the-country-era-says (accessed 26/11/2017).

ERA (Ethiopian Roads Authority) (2008) An Account of the Ethiopian Rural Travel and Transport Programme and Prospects: Assessment of the Pilot Implementation of the ERTTP. ERA, Addis Ababa, Ethiopia.

ERA (2019) Universal Rural Road Access Program. ERA, Addis Ababa, Ethiopia. See http://www.era.gov.et/documents/ 10157/72095/UNIVERSAL+RURAL+ROAD+ACCESS +PROGRAM.pdf (accessed 12/07/2019).

Evers B, Wondlimu A, Garsonnin J and Aberra A (2008) Contextual Gender Analytical Study of the Ethiopia Productive Safety Nets Programme. PSNP Gender Study. Government of the Federal Democratic Republic of Ethiopia, Addis Ababa, Ethiopia.

Fernando P and Porter G (eds) (2002) Balancing the Load: Women, Gender and Transport. Zed Books, London, UK.

Hailu B (2009) The Impact of Agricultural Policies on Smallholder Innovation Capacities: The Case of Household Level Irrigation Development in Two Communities of Kilte Awlaelo Woreda, Tigray Regional State, Ethiopia. MSc thesis, Wageningen University, Wageningen, the Netherlands.

Holmes R and Jones N (2011) Public works programmes in developing countries: reducing gendered disparities in economic opportunities? Proceedings of International Conference on Social Cohesion and Development, Paris, France.

Jones N, Tafere Y and Woldehanna T (2010) Gendered Risks, Poverty, and Vulneability in Ethiopia: To what extent is the Productive Safety Net (PSNP) making a difference? Overseas Development Institute, London, UK.

Mahapa SM and Mashiri M (2001) Social exclusion and rural transport: gender aspects of a road improvement project in Tshitwe, Northern Province. Development Southern Africa 18(3): 365-376.

Mard (Ministry of Agriculture and Rural Development) (2009) Food Security Programme 2010-2014: Productive Safety Net. Mard, Addis Ababa, Ethiopia.
Marshall K and Ali Z (2004) Gender issues in donkey use in rural Ethiopia. In Donkeys, People and Development. A Resource Book of the Animal Traction Network for Eastern and Southern Africa (ATNESA) (Fielding D and Starkey P (eds)). Technical Centre for Agricultural and Rural Cooperation (CTA), Wageningen, the Netherlands, pp. 62-68.

MoA (Ministry of Agriculture) (2014) Ethiopia: Productive Safety Net Programme Phase IV - Programme Implementation Manual. MoA, Addis Ababa, Ethiopia.

MOWA (Ministry of Women's Affairs) (2006) National Action Plan for Gender Equality (NAP-GE) 2006-2010. MOWA, Addis Ababa, Ethiopia. See http://extwprlegs1.fao.org/docs/pdf/eth149708.pdf (accessed 23/07/2019).

Porter G (1995) The impact of road construction on women's trade in rural Nigeria. Journal of Transport Geography 3(1): 3-14.

Porter G (2011) 'I think a woman who travels a lot is befriending other men and that's why she travels': mobility constraints and their implications for rural women and girls in sub-Saharan Africa. Gender, Place and Culture 18(1): 65-81.

Rammelt CF and Leung MWH (2017) Tracing the causal loops through local perceptions of rural road impacts in Ethiopia. World Development 95: 1-14.

Rammelt CF, van Schie M, Tegabu FN and Leung M (2017) Vaguely right or exactly wrong: measuring the (spatial) distribution of land resources, income and wealth in rural Ethiopia. Sustainability 9(6): 962 .

Sampson LR, Geddes RN, Negussie B and Asrat Y (2014) Low volume road research into practice: the Ethiopian experience. Proceedings of SARF/IRF Regional Conference, Pretoria, South Africa, pp. 288-300.

Starkey P and Hine J (2014) Poverty and Sustainable Transport: How Transport Affects Poor People with Policy Implications for Poverty Reduction. A Literature Review. ODI, London, UK. See https://sustainabledevelopment.un.org/content/documents/ 1767Poverty $\% 20$ and $\% 20$ sustainable $\% 20$ transport.pdf (accessed 17/07/2019).

Subbarao K, del Ninno C, Andrews C and Rodríguez-Alas C (2013) Public Works as A Safety Net: Design, Evidence, and Implementation. World Bank, Washington, DC, USA.

World Bank (2008) Ethiopia Agriculture and Rural Development Public Expenditure Review 1997/98 - 2005/06. World Bank, Washington, DC, USA.

World Bank (2010) Designing and Implementing A Rural Safety Net in A Low Income Setting: Lessons Learned From Ethiopia's Productive Safety Net Program 2005-2009. World Bank, Washington, DC, USA.

\section{How can you contribute?}

To discuss this paper, please email up to 500 words to the editor at journals@ice.org.uk. Your contribution will be forwarded to the author(s) for a reply and, if considered appropriate by the editorial board, it will be published as discussion in a future issue of the journal.

Proceedings journals rely entirely on contributions from the civil engineering profession (and allied disciplines). Information about how to submit your paper online is available at www.icevirtuallibrary.com/page/authors, where you will also find detailed author guidelines. 